\title{
Assessment of the Effectiveness of Ich Tam Khang as a Supportive Therapy for Chronic Heart Failure
}

\author{
Bien D. Vu ${ }^{1}$, Son N. Pham ${ }^{1}$, Thanh D. Le ${ }^{1}$, Ly K. Nguyen ${ }^{1}$, Dang H. Luong ${ }^{1}$, Quynh Luu ${ }^{1}$, \\ Duc V. Dang ${ }^{1}$ and Ba X. Hoang ${ }^{2, *}$
}

${ }^{1}$ Cardiovascular Institute, 108 Central Military Hospital, Hanoi, Vietnam

${ }^{2}$ Allergy Research Group, Alameda, California, USA

\begin{abstract}
Background: Heart failure is a chronic disease needing lifelong management. Despite the advances that have been made in the treatment of the disease, both the longevity and quality of life for those with chronic heart failure remain impaired. A more effective therapeutic approach with less negative side effects is still needed. In this study, we evaluate Ich Tam Khang (ITK), the poly-ingredient herbal and nutritional preparation with multiple physiological actions, as a supportive therapy for patients with chronic heart failure.
\end{abstract}

Aims of Study: To evaluate the effectiveness and safety of Ich Tam Khang as an adjunctive treatment of chronic heart failure.

Methods: A total of 60 patients with chronic congestive heart failure were enrolled in this open label, cross-sectional and prospective study. All patients were treated with a conventional regimen (digoxin, diuretics, angiotensin-convertingenzyme (ACE) inhibitors or angiotensin II receptor blockers (ARBs), beta blockers) for at least 4 weeks before being divided into two equal groups. In the treated patients with ITK, patients received conventional therapy plus 4 tablets ITK per day added in two divided doses. In the control patients, all patients kept the same conventional regimen without ITK. All patients were followed up for 3 months for clinical and para-clinical outcomes.

Result: The symptoms of heart failure (dyspnea, palpitation, peripheral edema, neck vein distention, heptojugular reflex) decreased. Heart rate and blood pressure stabilized during treatment in the treated patients with ITK. Additionally, total cholesterol and HDL-cholesterol normalized in the patients treated with ITK. Most of echocardiography parameters in the ITK treated patients were superior to the control patients. ITK is safe and it has no side effects.

Conclusion: ITK as a combination of herbal and nutritional preparation is effective in reducing heart failure symptoms, improving patient's quality of life for the patients with decompensated heart failure and reducing total cholesterol and LDL-C.

Keyword: Ich Tam Khang, heart failure, herbal medicine, nutritional supplement.

\section{INTRODUCTION}

Heart failure affects nearly 6 million Americans. Roughly 670.000 people are diagnosed with heart failure each year. It is the leading cause of hospitalization in people older than 60. With heart failure, blood moves through the heart and body at a slower rate, and pressure in the heart increases. As a result, the heart cannot pump enough oxygen and nutrients to meet the body's needs.

Worldwide, the number of re-hospitalizations due to decompensated heart failure is growing, which results in reducing quality of life, increasing morbidity and mortality. Chronic heart failure (CHF) is now recognized as a major and escalating public health problem. The costs of this syndrome, both in economic and personal terms, are considerable [1].

Modern pharmacological therapy remains the standard treatment in any stage of CHF. There are,

*Address correspondence to this author at the Allergy Research Group, 2300 North Loop Road, Alameda, California 94502, USA; Tel: 510 2630000;

Fax: 510263 2100; E-mail: niscba@aol.com however, many adverse reactions and complications that are associated with the medicines. Some drugs have narrow therapeutic ranges and have serious side effects [2]. Given these facts, research and development of herbal and nutritional medicines as an adjunctive treatment of heart failure could be very beneficial in the developed and developing countries.

ITK is formulated from herbal extracts and nutritional agents that are available in Vietnam, including: Salvia miltiorrhiza, Fibraurea tinctoria, Natto extract and L-carnitine. These ingredients are all permitted for use in the prevention and treatment of heart failure by the Vietnamese Food Administration.

Extract from Salvia miltiorrhiza has been shown to dilate arteries and improve microcirculation. It also reduces peripheral resistance, reduces energy consumption and oxygen requirements in patients with heart failure, myocardial infarction and myocardial ischemia $[3,4]$.

Natto extract is made by a special method from fermented soybeans. It has been shown in animal 
studies that Natto extract prevents thrombosis and promotes fibrinolysis $[5,6]$. Natto also helps to improve coronary circulation and increases the oxygen supply to heart muscle cells in patients with angina pectoris, myocardial infarction and heart failure $[5,6]$.

L-Carnitine plays an important role in transporting fatty acids to the mitochondria and increases the energy supply to heart muscle cells. L-carnitine also lowers blood cholesterol significantly and improves atherosclerosis [7-9].

Berberine is the main active substance of Fibraurea tinctoria Lour. Berberine prevents the development of plaque and atherosclerosis, lowers cholesterol, lowers blood pressure and has effectively treated heart failure in experimental research and clinical studies [10-12].

Because of all these benefits of the compound's ingredients, we designed this study to assess the efficacy and safety of ITK in supporting treatment of chronic heart failure.

\section{METHODS}

\section{Patient Selection}

60 heart failure patients (NYHA II, III) according to Framingham criteria (1993) due to different causes were enrolled from May to November 2011 in 108 Central Military Hospital in Hanoi. Patients were randomized into two categories: Treated patients with ITK $(\mathrm{N}=30)$ and control patients-standard therapy without ITK $(\mathrm{N}=30)$.

\section{Exclusion Criteria}

Patients with acute heart failure, severe heart failure (NYHA IV), congenital heart diseases, pericardial disease and patients with severe anemia were excluded.

\section{Study Design}

Cross - sectional, case - controlled, prospective study.

\section{Study Protocol}

The patients underwent physical examination, basic laboratory assessment and echocardiography. The patients were treated with standard therapy for two weeks then randomized into two groups. The treated patients with ITK continued a standard treatment regimen (inotrop, Angiotensin II receptor blockers (ARBs) or ACE inhibitors, coronary dilators, diuretics, beta blockers if not contraindicated) plus added ITK: 4 capsules daily in 2 divided doses. The control patients continued treatment with only the standard therapy.

\section{Table 1: Characteristics of the Patients}

\begin{tabular}{|c|c|c|c|c|}
\hline & & $\begin{array}{l}\text { Control patients } \\
\qquad(n=30)\end{array}$ & $\begin{array}{l}\text { Treated with } \\
\text { ITK patients } \\
\quad(n=30)\end{array}$ & $\mathbf{p}$ \\
\hline \multicolumn{2}{|c|}{ Age (years) } & $58.94 \pm 18.4$ & $59.18 \pm 16.08$ & $>0.05$ \\
\hline \multirow[t]{2}{*}{ Sex } & Male $(\mathrm{n}, \%)$ & $19(63.3 \%)$ & $18(60 \%)$ & \multirow{2}{*}{$>0.05$} \\
\hline & Female $(\mathrm{n}, \%)$ & $11(36.7 \%)$ & $12(40 \%)$ & \\
\hline \multicolumn{2}{|c|}{ Systolic blood pressure (mmHg) } & $109.53 \pm 9.9$ & $110.06 \pm 9.8$ & $>0.05$ \\
\hline \multicolumn{2}{|c|}{ Diastolic blood pressure $(\mathrm{mmHg})$} & $68.5 \pm 6.06$ & $69.4 \pm 14.08$ & $>0.05$ \\
\hline \multicolumn{2}{|c|}{ Heart rate (bpm) } & $87.23 \pm 6.78$ & $86,9 \pm 7,26$ & $>0.05$ \\
\hline \multicolumn{2}{|c|}{ Angina $(n, \%)$} & $15(50.0 \%)$ & $16(53.33 \%)$ & $>0.05$ \\
\hline \multicolumn{2}{|c|}{ Dyspnea $(n, \%)$} & $24(80.0 \%)$ & $25(83.33 \%)$ & $>0.05$ \\
\hline \multicolumn{2}{|c|}{ Neck - vein distension $(n, \%)$} & $20(66.66 \%)$ & $21(70.0 \%)$ & $>0.05$ \\
\hline \multicolumn{2}{|c|}{ Lung rales $(n, \%)$} & $05(16.66 \%)$ & $06(20.0 \%)$ & $>0.05$ \\
\hline \multirow[t]{2}{*}{ NYHA } & Class II $(n, \%)$ & $18(60.0 \%)$ & $21(70,0 \%)$ & $>0.05$ \\
\hline & Class III $(n, \%)$ & $12(40 \%)$ & $9(30.0 \%)$ & $>0.05$ \\
\hline \multicolumn{2}{|c|}{ Hepatojugular reflux $(n, \%)$} & $20(66,66 \%)$ & $22(73.33 \%)$ & $>0.05$ \\
\hline \multicolumn{2}{|c|}{ Peripheral edema $(n, \%)$} & $17(56.66 \%)$ & $19(63.33 \%)$ & $>0.05$ \\
\hline \multicolumn{2}{|c|}{ Nocturnal cough $(n, \%)$} & $14(46.66 \%)$ & $15(50.0 \%)$ & $>0.05$ \\
\hline \multicolumn{2}{|c|}{ Hepatomegaly $(n, \%)$} & $18(60.0 \%)$ & $20(66.66 \%)$ & $>0.05$ \\
\hline
\end{tabular}


In 3 months after treatment initiation, they were reevaluated by clinical condition, echocardiography, biochemical tests, clinical blood tests and adverse effects of drugs.

\section{Data Analysis}

Data analysis performed by SPSS 16.0 software.

\section{Patient Characteristics}

60 patients, aged from 45 to 78 , were divided into two equal groups with characteristics described on Table 1. The clinical characteristics of the treated and control patients were similar and no differences were statistically significant.

The etiology and duration of heart failure between the two sets of patients had no major difference. The average duration of heart failure was more than one year in both groups (Table 2).

The echocardiography parameters between the two patient categories have no statistically significant difference (Table 3).

\section{RESULTS}

After 3 months of treatment with ITK, symptoms of heart failure (dyspnea, edema, hepatomegaly and angina) and the NYHA functional class significantly improved (Table 4). In the treated patients with ITK, the clinical symptoms of heart failure and the hemodynamic parameters such as blood pressure and heart rate significantly improved compared with the control patients (Table 5).

Left atrial and left ventricular dimension (LAD, Dd, Ds) on echocardiography were significantly reduced in the treated patients with ITK compared with the control patients (Table 6). The hemodynamic parameters on echocardiography (EDV, ESV, EF\%, SV, CO) were significantly increased in the treated patients with ITK compared with the control patients.

Left ventricular and left atrial dimension (LAD, Dd, Ds), EDV, ESV, E-IVS, FS reduced significantly after treatment with ITK. The left ventricular contractility on echocardiography (EF\%, SV, CO) were significantly increased after treatment with ITK (Table 6).

Table 2: Etiology and Duration of Heart Failure

\begin{tabular}{|l|l|c|c|c|}
\hline \multicolumn{2}{|l|}{} & Control patients & Treated with ITK patients & P \\
\hline \hline \multirow{3}{*}{ Etiology } & Hypertension & $12(40 \%)$ & $13(43.33 \%)$ & $>0.05$ \\
\cline { 2 - 5 } & Coronary disease & $9(30 \%)$ & $9(30 \%)$ & $>0.05$ \\
\cline { 2 - 5 } & Cardiomyopathy & $5(16.67 \%)$ & $5(16.67 \%)$ & $3(10 \%)$ \\
\cline { 2 - 5 } & Others & $4(13.33 \%)$ & $1.46 \pm 0.31$ & $>0.05$ \\
\hline Duration (years) & & $1.50 \pm 0.27$ & 0.05 \\
\hline
\end{tabular}

The etiology and duration of heart failure between the treated and control patients have no significant differences.

Table 3: Echocardiography Parameters

\begin{tabular}{|l|c|c|c|}
\hline & $\begin{array}{c}\text { Control patients } \\
(\mathbf{n}=\mathbf{3 0})\end{array}$ & $\begin{array}{c}\text { Treated patients with ITK } \\
(\mathbf{n}=\mathbf{3 0})\end{array}$ & $\mathbf{p}$ \\
\hline \hline Lad $(\mathrm{mm})$ & $37.6 \pm 5.2$ & $36.3 \pm 9.78$ & $>0.05$ \\
\hline Dd $(\mathrm{mm})$ & $59.4 \pm 6.75$ & $58.7 \pm 9.6$ & $>0.05$ \\
\hline Ds $(\mathrm{mm})$ & $45.35 \pm 8.54$ & $41.22 \pm 11.1$ & $>0.05$ \\
\hline EDV $(\mathrm{ml})$ & $129.74 \pm 17.25$ & $127.5 \pm 17.6$ & $>0.05$ \\
\hline ESV $(\mathrm{ml})$ & $55.7 \pm 16.57$ & $54.16 \pm 18.4$ & $>0.05$ \\
\hline E-IVS $(\mathrm{mm})$ & $11.32 \pm 3.23$ & $9.93 \pm 3.85$ & $>0.05$ \\
\hline FS $(\%)$ & $37.13 \pm 8.63$ & $38.4 \pm 9.57$ & $>0.05$ \\
\hline EF $(\%)$ & $39.3 \pm 12.35$ & $41.2 \pm 15.6$ & $>0.05$ \\
\hline Mvcf $(\mathrm{cir} / \mathrm{s})$ & $0.79 \pm 0.21$ & $0.89 \pm 0.33$ & $>0.05$ \\
\hline SV $(\mathrm{ml})$ & $40.12 \pm 16.45$ & $43.3 \pm 22.87$ & $>0.05$ \\
\hline CO $(\mathrm{l} / \mathrm{m})$ & $3.89 \pm 0.82$ & $4.13 \pm 0.9$ & \\
\hline
\end{tabular}

The echocardiography parameters are similar for the ITK and the control patients. 
Table 4: Changes in Symptoms after Treatment in Treated Patients with ITK

\begin{tabular}{|c|c|c|c|c|c|}
\hline Symptoms & \multicolumn{2}{|c|}{ Before treatment $(n=30)$} & \multicolumn{2}{|c|}{ After treatment $(n=30)$} & $\mathbf{p}$ \\
\hline Angina & 16 & 53.33 & 6 & 20.00 & $<0.05$ \\
\hline Dyspnea & 25 & 83.33 & 12 & 40.0 & $<0.01$ \\
\hline Neck - vein distension & 21 & 70.0 & 14 & 46.67 & $<0.05$ \\
\hline Rales & 06 & 20.0 & 0 & 0 & $<0.01$ \\
\hline Edema & 19 & 63.33 & 5 & 16.67 & $<0.05$ \\
\hline Nocturnal cough & 15 & 50.0 & 6 & 20.00 & $<0.05$ \\
\hline Hepatomegaly & 20 & 66.67 & 9 & 30.00 & $<0.05$ \\
\hline Tachycardia & 19 & 63.33 & 7 & 23.33 & $<0.01$ \\
\hline
\end{tabular}

After 3 months of treatment with ITK, symptoms of heart failure of the patients significantly improved.

Table 5: Comparison of Heart Failure Symptoms after 3 Months Treatment

\begin{tabular}{|c|c|c|c|}
\hline Symptoms & $\begin{array}{l}\text { Control group } \\
\qquad(n=30)\end{array}$ & $\begin{array}{l}\text { Treated patients with ITK } \\
\qquad(\mathrm{n}=30)\end{array}$ & $\mathbf{p}$ \\
\hline Systolic blood pressure $(\mathrm{mmHg})$ & $105.2 \pm 9.9$ & $100.1 \pm 9.8$ & $<0.05$ \\
\hline Heart rate (bpm) & $82.3 \pm 9.54$ & $76.7 \pm 7.45$ & $<0.05$ \\
\hline Angina (n, \%) & $10(33.33 \%)$ & $6(20 \%)$ & $<0.05$ \\
\hline Neck - vein distension (n, \%) & $18(60 \%)$ & $14(46.67 \%)$ & $<0.05$ \\
\hline Hepatojugular reflux (n, \%) & $17(56.67 \%)$ & $14(46.67 \%)$ & $<0.05$ \\
\hline Edema (n, \%) & $9(30 \%)$ & $5(16.67 \%)$ & $<0.05$ \\
\hline Nocturnal cough (n, \%) & $12(40 \%)$ & $6(20 \%)$ & $<0.05$ \\
\hline
\end{tabular}

Table 6: Comparison of Echocardiographic Parameters in Treated Patients with ITK before and after Treatment

\begin{tabular}{|c|c|c|c|}
\hline & $\begin{array}{l}\text { Before treatment } \\
\qquad(n=30)\end{array}$ & $\begin{array}{l}\text { After treatment } \\
\qquad(\mathrm{n}=\mathbf{3 0})\end{array}$ & p \\
\hline LAd (mm) & $36.3 \pm 9.78$ & $32.49 \pm 3.4$ & $<0.05$ \\
\hline $\mathrm{Dd}(\mathrm{mm})$ & $58.7 \pm 9.6$ & $51.71 \pm 3.36$ & $<0.05$ \\
\hline Ds (mm) & $41.22 \pm 11.1$ & $38.87 \pm 2.99$ & $<0.05$ \\
\hline E-IVS (mm) & $9.93 \pm 3.85$ & $6.7 \pm 1.03$ & $<0.05$ \\
\hline FS (\%) & $38.4 \pm 9.57$ & $32.13 \pm 6.35$ & $<0.05$ \\
\hline $\mathrm{EF}(\%)$ & $41.2 \pm 15.6$ & $50.05 \pm 6.42$ & $<0.05$ \\
\hline Mvcf (cir/s) & $0.89 \pm 0.33$ & $1.18 \pm 0.15$ & $<0.05$ \\
\hline
\end{tabular}


Table 7: Serum Lipid Profiles after 3 Months of Treatment

\begin{tabular}{|l|c|c|c|}
\hline & $\begin{array}{c}\text { Control patients } \\
(\mathbf{n = 3 0 )}\end{array}$ & $\begin{array}{c}\text { Treated patients with ITK } \\
(\mathbf{n}=\mathbf{3 0})\end{array}$ & $\mathbf{P}$ \\
\hline \hline Cholesterol $(\mathrm{mmol} / \mathrm{l})$ & $4.85 \pm 0.87$ & $4.22 \pm 0.82$ & $<0.05$ \\
\hline Triglyceride $(\mathrm{mmol} / \mathrm{l})$ & $2.50 \pm 0.78$ & $2.47 \pm 0.72$ & $>0.05$ \\
\hline LDL-C $(\mathrm{mmol} / \mathrm{l})$ & $3.12 \pm 0.82$ & $2.23 \pm 0.94$ & $<0.05$ \\
\hline $\mathrm{HDL}-\mathrm{C}(\mathrm{mmol} / \mathrm{l})$ & $1.05 \pm 0.49$ & $1.54 \pm 0.52$ & $<0.05$ \\
\hline
\end{tabular}

Table 8: Serum Lipid Profiles of the Treated Patients with ITK before and after Treatment

\begin{tabular}{|l|c|c|c|}
\hline & $\begin{array}{c}\text { Before treatment } \\
(\mathbf{n}=\mathbf{3 0})\end{array}$ & $\begin{array}{c}\text { After treatment } \\
(\mathbf{n}=\mathbf{3 0})\end{array}$ & $\mathbf{P}$ \\
\hline \hline Cholesterol $(\mathrm{mmol} / \mathrm{l})$ & $5.48 \pm 1.1$ & $4.22 \pm 0.82$ & $<0.05$ \\
\hline Triglyceride $(\mathrm{mmol} / \mathrm{l})$ & $2.56 \pm 1.41$ & $2.47 \pm 0.72$ & $>0.05$ \\
\hline LDL-C $(\mathrm{mmo} / \mathrm{l})$ & $3.58 \pm 0.93$ & $2.23 \pm 0.94$ & $<0.05$ \\
\hline HDL-C $(\mathrm{mmol} / \mathrm{l})$ & $1.07 \pm 0.53$ & $1.54 \pm 0.52$ & $<0.05$ \\
\hline
\end{tabular}

Table 9: Biochemistry Parameters of the Treated Patients with ITK before and after Treatment

\begin{tabular}{|l|c|c|c|}
\hline & $\begin{array}{c}\text { Before treatment } \\
(\mathbf{n}=\mathbf{3 0})\end{array}$ & $\begin{array}{c}\text { After treatment } \\
(\mathbf{n}=\mathbf{3 0})\end{array}$ & $\mathbf{P}$ \\
\hline \hline Glucose $(\mathrm{mmol} / \mathrm{l})$ & $6.87 \pm 1.65$ & $6.82 \pm 1.7$ & $>0.05$ \\
\hline Urea $(\mathrm{mmol} / \mathrm{l})$ & $8.3 \pm 1.2$ & $8.5 \pm 1.5$ & $>0.05$ \\
\hline Creatinine $(\mu \mathrm{mol} / \mathrm{l})$ & $98.5 \pm 9.4$ & $97.6 \pm 10.3$ & $>0.05$ \\
\hline SGOT $(\mathrm{Ul} / \mathrm{l})$ & $56.4 \pm 7.3$ & $54.6 \pm 9.8$ & $>0.05$ \\
\hline SGPT $(\mathrm{Ul} / \mathrm{l})$ & $59.6 \pm 8.2$ & $53.9 \pm 10.6$ & $>0.05$ \\
\hline Red blood cell $(\mathrm{T} / \mathrm{l})$ & $4.66 \pm 0.25$ & $4.54 \pm 0.28$ & $>0.05$ \\
\hline Hemoglobin $(\mathrm{g} / \mathrm{l})$ & $125 \pm 14.5$ & $136.9 \pm 13.9$ & $>0.05$ \\
\hline White blood cell $(\mathrm{G} / \mathrm{l})$ & $7.48 \pm 1.57$ & $7.44 \pm 1.24$ & $>0.05$ \\
\hline Platelet $(\mathrm{G} / \mathrm{l})$ & $167 \pm 21.75$ & $160 \pm 25.12$ & \\
\hline
\end{tabular}

Total cholesterol and LDL-C in the treated patients with ITK were reduced significantly compared with the controlled patients (Table 7). Additionally, total cholesterol and LDL-C were reduced significantly in the treated patients with ITK compared with before treatment (Table 8).

Blood glucose, liver function, renal function and hematologic testing showed no difference between before and after 3 months of treatment with ITK (Table 9). There were no reported side effects (allergies, digestive symptoms, nausea, vomiting, etc.) in the treated patients with ITK.

\section{DISCUSSION}

Heart failure is epidemic in developed countries and is expanding rapidly worldwide. Roughly $5 \%$ of patients with heart failure have end-stage disease that is refractory to medical therapy (stage $D$ heart failure)
$[13,14]$. The number of deaths due to heart failure in the USA in 2004 was 284.365, which exceeds the deaths due to lung cancer, breast cancer, prostate cancer and HIVIAIDS combined [13,14]. Therefore, there is a need for research and development of adjunctive treatment that might improve the symptom control, quality of life and longevity of CHF patients. Herbal and nutritional products offer a possible avenue of exploration for this goal. Considering the fact that there are numerous preclinical and clinical studies proving that for patients with CHF these natural products are beneficial, safe and have no major harmful interaction with the standard treatments.

Our current study was designed to evaluate a combination of herbal extracts with nutritional agents (ITK) that are known to produce multiple beneficial actions to the pathogenesis of CHF. The results of our study showed that ITK was effective and safe as an adjunctive therapy for the patients with $\mathrm{CHF}$. The 
symptoms of heart failure were significantly reduced: Edema $(63.33 \%$ versus $16.67 \%)$; dyspnea (83.33\% versus $40 \%$ ); NYHA class III to class II in 4 patients $(13.33 \%)$ and echocardiographic parameters were improved markedly compared with the control patients (EF\%, $50.05 \pm 10.42$ versus $42.3 \pm 6.35$, Dd $58.7 \pm 9.6$ versus $51.71 \pm 3.36$ with $p<0.05)$. Other symptoms such as tachycardia and chest pain were decreased significantly in the treated patients with ITK compared to the control patients.

The most important findings of the study were that the echocardiography parameters including size and volume of the heart chambers were decreased after three months treatment with ITK compared with the control patients. The heart function parameters include left ventricular ejection fraction (EF \%), cardiac output (CO), stroke volume (SV), Mean Velocity of Circumferential Fiber shortening (Mvcf) were significantly increased after three months treatment with ITK. These results strongly suggested ITK can be used for the rehabilitation and palliative care of patients with decompensated stage of CHF.

Additionally, the study found that total cholesterol and LDL-C were reduced in the treated patients with ITK after three months treatment compared with the control patients and compared with the levels before treatment.

Our study indicated that ITK is safe for patients with $\mathrm{CHF}$ and can be combined with standard treatment modalities.

\section{CONCLUSIONS}

ITK is safe and effective as an adjunctive therapy for $\mathrm{CHF}$ in relieving symptoms, improving quality of life and heart functional parameters of the patients. There is a possibility of synergic and potentiating therapeutic action of the components of the ITK that would be of interest for future exploratory research for the management of $\mathrm{CHF}$ and other cardiovascular diseases.

\section{REFERENCES}

[1] Clark AP, McDougall G, Riegel B, Joiner-Rogers G, Innerarity S, Meraviglia M, et al. Health Status and Self-care
Outcomes After an Education-Support Intervention for People With Chronic Heart Failure. J Cardiovasc Nurs 2014. http://dx.doi.org/10.1097/JCN.0000000000000169

[2] Liu X, Yu H, Pei J, Chu J, Pu J, Zhang S. Clinical Characteristics and Long-term Prognosis in Patients with Chronic Heart Failure and Reduced Ejection Fraction in China. Heart Lung Circ 2014; S1443-9506(1414)0015900150 [pii] DOI: 00110.01016/j.hlc.02014.00102.00022

[3] Wang J, Xiong X, Feng B. Cardiovascular effects of salvianolic Acid B. Evid Based Complement Alternat Med 2013; 2013: 247948.

[4] Lu Y, Zheng Y, Liu X, Liang X, Ngai S, Li T, Zhang W. Metabolomic profiles of myocardial ischemia under treatment with salvianolic acid B. Chin Med 2012; 7: 6. http://dx.doi.org/10.1186/1749-8546-7-6

[5] Jang JY, Kim TS, Cai J, Kim J, Kim Y, Shin K, et al Nattokinase improves blood flow by inhibiting platelet aggregation and thrombus formation. Lab Anim Res 2013; 29: 221-225.

http://dx.doi.org/10.5625/lar.2013.29.4.221

[6] Park KJ, Kang JI, Kim TS, Yeo IH. The antithrombotic and fibrinolytic effect of natto in hypercholesterolemia rats. Prev Nutr Food Sci 2012; 17: 78-82.

http://dx.doi.org/10.3746/pnf.2012.17.1.078

[7] Ferrari R, Merli E, Cicchitelli G, Mele D, Fucili A, Ceconi C Therapeutic effects of L-carnitine and propionyl-L-carnitine on cardiovascular diseases: a review. Ann $N$ Y Acad Sci 2004; 1033: 79-91.

http://dx.doi.org/10.1196/annals. 1320.007

[8] Hiatt WR. Carnitine and peripheral arterial disease. Ann N Y Acad Sci 2004; 1033: 92-98. http://dx.doi.org/10.1196/annals.1320.008

[9] lliceto S, Scrutinio D, Bruzzi P, D'Ambrosio G, Boni L, Di Biase $\mathrm{M}$, et al. Effects of $\mathrm{L}$-carnitine administration on left ventricular remodeling after acute anterior myocardial infarction: the L-Carnitine Ecocardiografia Digitalizzata Infarto Miocardico (CEDIM) Trial. J Am Coll Cardiol 1995; 26: 380387.

http://dx.doi.org/10.1016/0735-1097(95)80010-E

[10] Lau CW, Yao XQ, Chen ZY, Ko WH, Huang $Y$ Cardiovascular actions of berberine. Cardiovasc Drug Rev 2001; 19: 234-244. http://dx.doi.org/10.1111/j.1527-3466.2001.tb00068.x

[11] Marin-Neto JA, Maciel BC, Secches AL, Gallo Junior L. Cardiovascular effects of berberine in patients with severe congestive heart failure. Clin Cardiol 1988; 11: 253-260. http://dx.doi.org/10.1002/clc.4960110411

[12] Zeng $\mathrm{XH}$, Zeng $\mathrm{XJ}$, Li YY. Efficacy and safety of berberine for congestive heart failure secondary to ischemic or idiopathic dilated cardiomyopathy. Am J Cardiol 2003; 92: 173-176.

http://dx.doi.org/10.1016/S0002-9149(03)00533-2

[13] Costanzo MR, Mills RM, Wynne J. Characteristics of "Stage D" heart failure: insights from the Acute Decompensated Heart Failure National Registry Longitudinal Module (ADHERE LM). Am Heart J 2008; 155: 339-347. http://dx.doi.org/10.1016/j.ahj.2007.10.020

[14] Adler ED, Goldfinger JZ, Kalman J, Park ME, Meier DE. Palliative care in the treatment of advanced heart failure. Circulation 2009; 120: 2597-2606.

http://dx.doi.org/10.1161/CIRCULATIONAHA.109.869123

Received on 23-08-2014
DOI: http://dx.doi.org/10.6000/1929-5634.2014.03.03.2

(C) 2014 Vu et al.; Licensee Lifescience Global.

This is an open access article licensed under the terms of the Creative Commons Attribution Non-Commercial License (http://creativecommons.org/licenses/by-nc/3.0/) which permits unrestricted, non-commercial use, distribution and reproduction in any medium, provided the work is properly cited. 